\title{
Potentiation of the Acoustic Startle Response by a Conditioned Stimulus Paired With Acoustic Startle Stimulus in Rats
}

\author{
Robert N. Leaton \\ Dartmouth College
}

\author{
Jacquelyn Cranney \\ University of New South Wales \\ Kensington, New South Wales, Australia
}

\begin{abstract}
The hypothesis that the standard acoustic startle habituation paradigm contains the elements of Pavlovian fear conditioning was tested. In a potentiated startle response paradigm, a startle stimulus and a light conditioned stimulus (CS) were paired. A startle stimulus then was tested alone or following the CS. Freezing behavior was measured to index conditioned fear. The startle response was potentiated on CS trials, and rats froze more in CS than in non-CS periods. In Experiment 1, response to a previously habituated, weak startle stimulus was potentiated. In Experiment 2, response to the same stimulus used as the unconditioned stimulus (US) in training was potentiated. This CS-potentiated response retarded the course of response decrements over training sessions as compared with an explictly unpaired control group. Conditioned fear is a standard feature of this habituation paradigm, serves to potentiate the startle response, and provides an associative dimension lacking in the habituation process per se.
\end{abstract}

Borszcz, Cranney, and Leaton (1989) hypothesized that the standard acoustic startle habituation paradigm contains the elements of Pavlovian fear conditioning. According to this hypothesis, fear conditioning arises from the association between the contextual cues of the startle apparatus and the startle stimulus itself. The contextual cues serve as the conditioned stimulus (CS), and the startle stimulus serves as the unconditioned stimulus (US). Freezing behavior develops during the course of habituation training as a reflection of the fear conditioning, and the response-energizing effects of fear elevate startle amplitudes. Under some circumstances, the response-enhancing effects of conditioned fear can mask the response-reducing effects of habituation. In support of this hypothesis, Borszcz et al. (1989) showed that (a) brain lesions that reduce fear behavior retarded the development of freezing behavior and facilitated habituation, (b) preexposure to the startle apparatus (the CS) served as a latent inhibition manipulation to retard the development of freezing and to facilitate habituation, and (c) after initial habituation training, exposure to the startle apparatus alone served to extinguish freezing and reduce startle amplitudes. It was argued that this fear conditioning brings an associative dimension to the habituation paradigm in the form of a long-term sensitization process that interacts with long-term habituation to determine response level.

Portions of this article were presented at the Eastern Psychological Association Annual Meeting, Boston, 1989. The research was supported in part by a grant from the Australian Research Council to Jacquelyn Cranney and by a Dartmouth College Senior Faculty Grant to Robert N. Leaton. Leaton was a Visiting Professor in the School of Psychology, University of New South Wales, during the course of the research and thanks are due that school for support and assistance.

We thank Sandra Graudins for assistance in animal testing and George Borszcz for critical comments on the manuscript.

Correspondence concerning this article should be addressed to either Robert N. Leaton, Department of Psychology, Dartmouth College, Hanover, New Hampshire 03755, or Jacquelyn Cranney, School of Psychology, University of New South Wales, P.O. Box 1, Kensington, New South Wales 2033, Australia.
A variety of corollary data are consistent with this hypothesis. Many experiments have shown that fear potentiates the startle response (e.g., Brown, Kalish, \& Farber, 1951; Davis \& Astrachan, 1978). In the typical potentiated startle paradigm, a CS is paired with shock in an initial training phase. In subsequent tests, a startle stimulus either is presented alone or in the presence of the CS. Startle amplitude is higher in the presence of the CS. Freezing behavior has been shown to be a reliable index of fear (Blanchard \& Blanchard, 1969; Fanselow, 1980), and Leaton and Borszcz (1985) showed strong correlations between startle amplitude and freezing in a potentiated startle paradigm. Lesions of the amygdala, which reduce fear-related behaviors generally (Albert \& Walsh, 1984), and freezing (Blanchard \& Blanchard, 1972) and potentiated startle (Hitchcock \& Davis, 1986) specifically, also retard the development of freezing and facilitate response decrements in an acoustic startle habituation paradigm (Leaton \& Supple, 1987). In addition, an intense auditory stimulus appears to be similar to a weak shock in terms of its ability to engage the endogenous opioid systems (Cranney, 1987, 1988) and to serve as a US in various aversive conditioning paradigms (e.g., Bakal, Johnson, \& Rescorla, 1974; LoLordo, 1967; Lyon, 1964).

One of the implications of this hypothesis is that a startle stimulus should serve as a US for fear conditioning in any Pavlovian conditioning arrangement. A discrete CS paired with a startle stimulus, for example, should acquire the properties of a fear stimulus. In a potentiated startle paradigm, this CS should, in turn, serve to potentiate the response to a startle stimulus. The experiments described here tested this prediction and some of its implications.

\section{Experiment 1}

In Experiment 1 , animals were first given initial habituation training with one startle stimulus. In a training phase, a second, stronger startle stimulus was paired with a light $C S$ in a potentiated startle paradigm. In test sessions, the original startle stimulus was presented alone or in the presence of the 
CS. We expected that the stronger startle stimulus would support fear conditioning to the CS, so that the response to the original startle stimulus would be potentiated in the presence of the CS.

\section{Method}

Subjects. Eight adult male Wistar rats obtained from the University of New South Wales Animal Breeding and Holding Unit were housed in groups of four and maintained on a natural day/night cycle and ad lib food and water throughout the experiment. The rats were assigned to a paired group and an unpaired group matched on body weight. The respective group mean weights were $430 \mathrm{~g}$ and $423 \mathrm{~g}$.

Apparatus. The apparatus was similar to that described by Cranney (1988). Briefly, rats were tested in one of four identical startle chambers, $20 \mathrm{~cm} \times 12 \mathrm{~cm} \times 12 \mathrm{~cm}$, that was constructed of Plexiglas and had a grid floor. The chamber was suspended from a Plexiglas sheet to which a piezoelectric film was laminated. Abrupt movements of the rat caused the Plexiglas to flex slightly, inducing a voltage in the piezoelectric film (Leitner \& Rosenberger, 1983). This voltage was digitized by a microcomputer system, and the peak positive voltage within $100 \mathrm{~ms}$ after the startle stimulus was taken as a measure of the response. The chambers were housed in sound-attenuated boxes, two per box, which had large Perspex windows to allow observation of the rats. The chambers were illuminated by a $15-\mathrm{W}$ red light bulb.

One Tandy piezoelectric speaker (Type 40-1379) was mounted 6 $\mathrm{cm}$ from each of the two side walls of each startle chamber and were simultaneously activated for all auditory stimulation. Continuous white noise, $70 \mathrm{~dB}$ (SPL), helped masked extraneous sounds. Startle stimulus and background intensities were measured with a Bruel and Kjaer sound-level meter (Type 2235), with a microphone placed in a central position within the chamber. A $220-\mathrm{V}, 60-\mathrm{W}$ white light bulb mounted $11 \mathrm{~cm}$ from the rear of the startle chamber was used as a CS. Before each rat's session, the startle chamber was cleaned with a $0.5 \%$ solution of acetic acid.

Procedure. In the first phase, each rat was given six 5-min preexposure sessions in the startle chamber on each of 2 days. The sessions were given in sets of two separated by $15 \mathrm{~min}$, with the sets separated by $3 \mathrm{hr}$. No startle stimuli were presented.

After the 2 days of preexposure, each rat was given three sessions in the startle chamber each day. Sessions were separated by $3 \mathrm{hr}$. On the day after preexposure, the pretraining day, each of the three sessions consisted of 10 presentations of a $100-\mathrm{ms}, 102-\mathrm{dB}, 10-\mathrm{kHz}$ startle stimulus on a 140-s variable interval (VI) schedule. In this and all subsequent sessions, the first stimulus was presented after the first $2 \mathrm{~min}$ of the session. These sessions were designed to produce longterm habituation to the $10-\mathrm{kHz}$ stimulus.

On the following day, the training day, each of the three sessions consisted of 10 presentations of a $100-\mathrm{ms}, 117-\mathrm{dB}$ white noise startle stimulus and 10 presentations of a $20-s$ light CS. For the paired group, the startle stimulus immediately followed the offset of the light CS. For the unpaired group, the startle stimulus and the CS were explicitly unpaired, the CS being presented midway between startle stimuli and $60 \mathrm{~s}$ after the last startle stimulus. For both groups, the startle stimuli were presented on a 140-s VI schedule.

On the following day, the test day, each of the three sessions consisted of 10 presentations, on the 140-s VI schedule, of the 10$\mathrm{kHz}$ startle stimulus used on the pretraining day. Five of the stimuli were immediately preceded by the light CS (LT trials), and five were presented alone ( $\mathrm{T}$ trials). LT and T trials were alternated, and the order of alternation was balanced over sessions and between groups. During the 20-s CS presentation, and for the 20-s period before the startle stimulus on $T$ trials, the rats were observed using a timesampling procedure. Every $4 \mathrm{~s}$, the rat's behavior was scored as either freezing or not freezing. Freezing was defined as the absence of all visible movements of the body and vibrissae except for movement necessitated by respiration (Fanselow, 1984). The percentage of time samples judged as freezing was calculated for each trial. Each rat received a total of $15 \mathrm{LT}$ trials and $15 \mathrm{~T}$ trials over the three sessions.

\section{Results}

An analysis of variance (ANOVA) of the pretraining day data showed a significant reduction in responsiveness to the $10 \mathrm{kHz}$ startle stimulus over the three sessions, $F(2,12)=$ $5.92, p<.05$, but no group difference or interaction (both $F \mathrm{~s}<1.0$ ). A meaningful analysis of the training day was not possible because the intense white-noise stimulus provoked a maximum response on $72 \%$ of the trials in the paired group and on $52 \%$ of the trials in the unpaired group.

The results of the test sessions are summarized in Figure 1. Mean startle amplitudes for the $15 \mathrm{LT}$ trials and the $15 \mathrm{~T}$ trials are shown on the left in the figure. A $2 \times 2$ ANOVA ( 2 groups by 2 trial types) of these data yielded a significant Group $\times$ Trial-Type interaction, $F(1,6)=30.66, p<.01$. Neither the group difference $(F<1.0)$ nor the trial-type difference, $F(1,6)=4.08, p>.05$, was significant. For the paired group, startle amplitude was significantly higher on LT trials than on $\mathrm{T}$ trials (mean difference $\pm \mathrm{SE}=28.8 \pm 5.25$ ), $t(3)=5.49, p<.05$. (All $p$ values for $t$ tests are two-tailed probabilities.) The reverse pattern for the unpaired group (mean difference $=-13.4 \pm 5.52$ ) did not reach significance, $t(3)=2.55, p>.05$. Mean percentage potentiation [(LT-T)/ T) $\times 100$ ] for the paired group was $+61.0 \% \pm 27.50$ and for the unpaired group was $-16.8 \% \pm 6.15$. This difference was significant, $t(6)=2.76, p<.05$.

Mean percentage freezing during the 20-s CS (LT) and for the 20-s period before the tone on $\mathrm{T}$ trials is shown on the right in Figure 1. An ANOVA again yielded a significant group $\times$ Trial-Type interaction, $F(1,6)=20.45, p<.01$. The group effect did not reach significance, $F(1,6)=4.00, p>$ .05 , but the trial-type difference was significant, $F(1,6)=$ $8.14, p<.05$. The paired group froze significantly more during the CS periods than during the non-CS periods (mean difference $=32.3 \pm 8.43), t(3)=3.84, p<.05$. The reverse pattern for the unpaired group (mean difference $=-7.3 \pm 2.46$ ) did not reach significance, $t(3)=2.97, p>.05$.

For both the startle and freezing measures, the mean response for the $15 \mathrm{LT}$ trials and the $15 \mathrm{~T}$ trials provided the most stable index of responsiveness differences. Both for simplicity and to maintain consistency with the typical potentiated startle paradigm (e.g., Hitchcock \& Davis, 1986; Leaton \& Borszcz, 1985), these are the only data shown in Figure 1. In addition, expected reductions in startle amplitude, $F(2,12)$ $=36.75, p<.001$, and freezing, $F(2,12)=32.41, p<.001$, occurred over test sessions for both groups and for both trial types. 
Startle Response

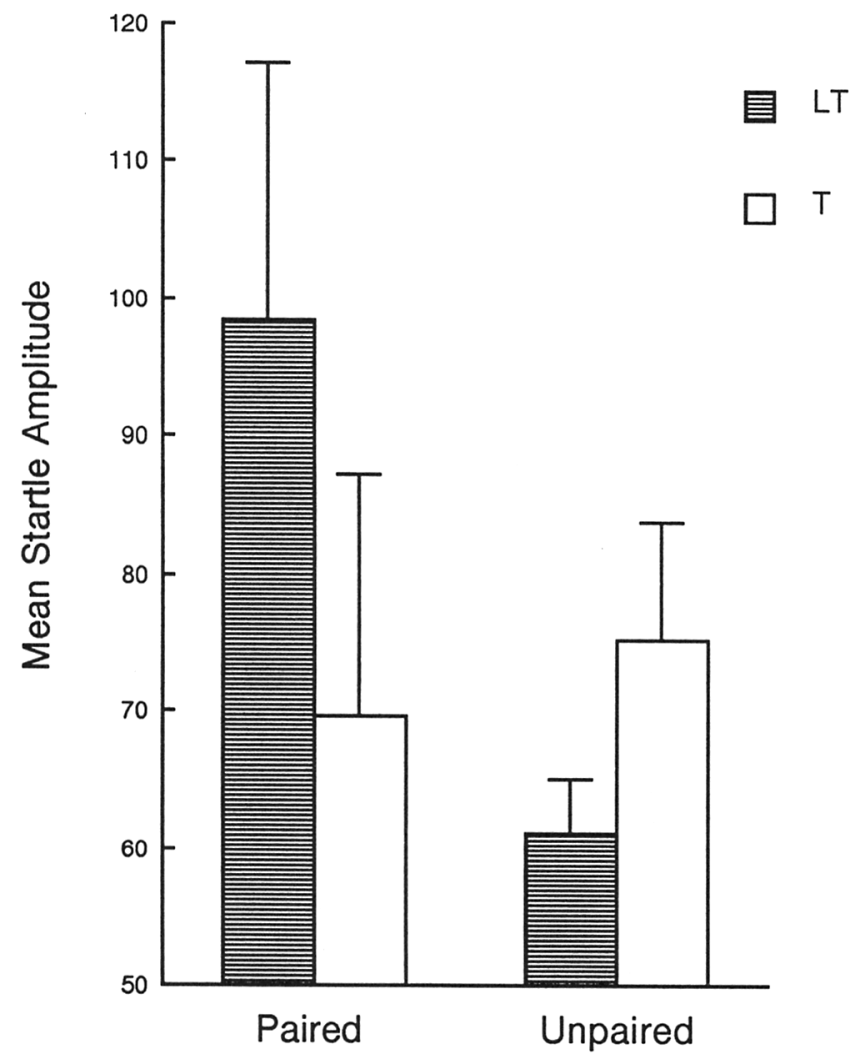

Freezing

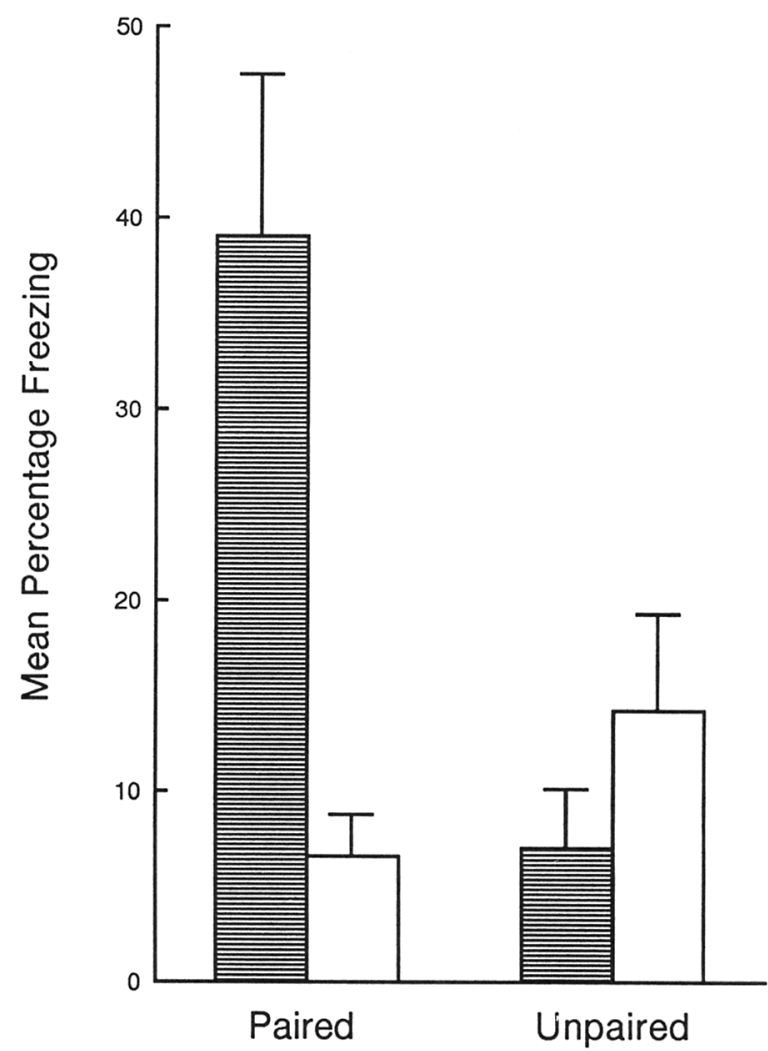

Figure 1. Mean startle amplitudes on light-tone trials (LT) and tone-alone trials (T) and mean percentage freezing during the light on LT trials and for the $20 \mathrm{~s}$ before the tonal startle stimulus on $\mathrm{T}$ trials for the paired and unpaired groups for the test day in Experiment 1. (Note that the ordinates for the two measures are scaled differently and have different starting points. Vertical lines indicate standard errors.)

\section{Discussion}

The startle response to a $10-\mathrm{kHz}$ stimulus was significantly potentiated when the stimulus was presented immediately after a CS that previously had been paired with a white noise startle stimulus. The percentage of potentiation was significantly greater in the paired group than in the explictly unpaired group. This latter group showed a nonsignificant trend to respond less in the presence of the CS than in its absence. The percentage of potentiation in the paired group, $61 \%$, compares favorably with the potentiation found in the typical potentiated startle paradigm with shock used as the US (e.g., Davis \& Astrachan, 1978; Hitchcock \& Davis, 1986; Leaton \& Borszcz, 1985). The freezing response paralleled the group differences in startle amplitude. The paired group froze significantly more during the CS than during non-CS periods, whereas the reverse pattern in the unpaired group was not significant.

These data support the theory just outlined, which assumes that a startle stimulus can be viewed as a US for fear condi- tioning. The conditioned fear, indexed by the freezing response, served to potentiate the startle response and provided a possible associative dimension to the habituation paradigm.

\section{Experiment 2}

Experiment 1 demonstrated that a startle stimulus can serve as a US to support fear conditioning and that this conditioning can, in turn, potentiate startle amplitudes. These results suggest that a CS paired with a startle stimulus should be able to potentiate the response to any stimulus, even that stimulus that served as the US to establish the CS. It then follows that pairing a startle stimulus with a CS during habituation training should retard the course of response decrements to that startle stimulus. The response-enhancing effects of the CS should provoke and maintain an elevated response level to the startle stimulus as compared with the response level for an unsignaled startle stimulus. An independent hypothesis, but one necessary to account for the course of response decrements during habituation training, assumes that with 
repeated presentations the startle stimulus loses its ability to serve as a US for fear conditioning. To test these predictions, we replicated the procedures of Experiment 1 in Experiment 2 except that (a) the same startle stimulus was used in both potentiation training and in testing and (b) the course of response change to the CS-paired startle stimulus was followed over a number of days.

\section{Method}

Subjects and apparatus. Twenty-four adult male Wistar rats were housed in groups of 8 but were otherwise similar to those used in Experiment 1 . They were assigned to a paired group and an unpaired group matched on body weight (Mean $=335 \mathrm{~g}$ ). The apparatus was identical to that used in Experiment 1, except that amplification of the startle response signal was reduced to avoid ceiling effects in this response measure, and the background noise level was reduced to 65 dB.

Procedure. The basic daily running schedule replicated that used in Experiment 1. The procedures differed from Experiment 1 in that the same white noise stimulus was used in both training and testing, and there were no startle sessions before the first training day. Each rat began with six 5-min preexposure sessions on each of 2 days. On each day after preexposure, each rat was given three sessions in the startle chamber separated by $3 \mathrm{hr}$. The third day, Training Day 1, was procedurally identical to the training day in Experiment 1, except that the intensity of the white noise startle stimulus was reduced to $110 \mathrm{~dB}$ to further minimize ceiling effects, and freezing behavior was observed. For the paired group, each presentation of the startle stimulus was preceded by the 20 -s light CS. For the unpaired group, the startle stimulus and the CS were explicitly unpaired. The rats were judged as either freezing or not freezing following the same observational time-sampling procedure used in Experiment 1. Onethird of the observations were made by an hypothesis-blind observer. The observations were made during the 20-s CS period for both groups, for the 20-s pre-CS period for the paired group, and for the 20-s period before the startle stimulus for the unpaired group. On the fourth day, Test Day 1, each of the three sessions consisted of 10 presentations, on the 140-s schedule, of the same 110-dB white noise startle stimulus used on Training Day 1. Five of the stimuli were immediately preceded by the light CS (LN trials), and five were presented alone ( $\mathrm{N}$ trials). $\mathrm{LN}$ and $\mathrm{N}$ trials were alternated, and the order of alternation was balanced over sessions and between groups. During the 20-s CS presentation, and for the 20-s period before the startle stimulus on $\mathrm{N}$ trials, the rats were judged as either freezing or not freezing. Each rat received a total of $15 \mathrm{LN}$ trials and $15 \mathrm{~N}$ trials over the three sessions. This procedure replicated the test day procedure of Experiment 1 except for the nature of the startle stimulus.

On the fifth and sixth days, Training Days 2 and 3, the same procedure as for Training Day 1 was used. On the seventh day, Test Day 2, the same procedure was used as for Test Day 1. In summary, each rat was given one training day, followed by one test day, followed by two more training days, followed by a final test day.

\section{Results}

To facilitate comparison with Experiment 1, we first consider the results of Test Day 1 . These results are shown in Figure 2. Mean startle amplitudes for the $15 \mathrm{LN}$ trials and the $15 \mathrm{~N}$ trials are shown on the left in the figure. The results basically replicated Experiment 1 . A $2 \times 2$ ANOVA yielded a significant Group $\times$ Trial-Type interaction, $F(1,22)=$ $38.76, p<.001$. Both the group difference, $F(1,22)=6.41$, $p<.05$, and the trial-type difference, $F(1,22)=67.79, p<$ .001 , were significant. For the paired group, startle amplitude was significantly higher on $\mathrm{LN}$ trials than on $\mathrm{N}$ trials (mean difference $=44.5 \pm 3.48), t(11)=12.91, p<.001$. For the unpaired group, this difference was not significant (mean difference $=6.2 \pm 5.10), t(11)=1.21, p>.05$. Mean percentage potentiation for the paired group was $67.9 \% \pm 10.49$ and for the unpaired group was $12.7 \% \pm 10.20$. This group difference was significant, $t(22)=3.78, p<.01$.

Mean percentage freezing during the 20-s CS (LN) and for the 20-s period before the startle stimulus on $\mathrm{N}$ trials is shown on the right in Figure 2. An ANOVA again yielded a significant Group $\times$ Trial-Type interaction, $F(1,22)=85.31, p<$ .001 . Both the group difference, $F(1,22)=8.72, p<.01$, and the trial-type difference, $F(1,22)=19.84, p<.001$, were significant. The paired group froze significantly more during the CS periods than during the non-CS periods (mean difference $=32.4 \pm 3.68), t(11)=8.84, p<.001$. The reverse pattern for the unpaired group was also significant (mean difference $=11.3 \pm 3.00), t(11)=3.78, p<.01$.

Presenting the data as the means for the two trial types over the three sessions of Test Day 1 facilitates comparison with Experiment 1 but hides changes over sessions. As in Experiment 1 , both the startle response measure, $F(2,44)=12.05$, $p<.01$, and the freezing measure, $F(2,44)=36.48, p<.01$, decreased across sessions for both groups and both trial types. (See the second panels in Figures 3 and 4). For neither measure was the Group $\times$ Session or Trial Type $\times$ Session interaction significant (all $p s>.10$ ), but the triple interaction for freezing did reach significance, $F(2,44)=5.23, p<.01$.

The full course of the training-test sequence is summarized by session means in Figures 3 and 4. Figure 3 shows the startle amplitudes for the three training days and the two test days as a function of trial type and group. Pairing the startle stimulus with a CS elevated startle response amplitudes. Although the unpaired group showed modest decreases in startle amplitudes over training sessions, the startle response for the paired group increased over the initial training sessions and began to decrease only during Training Day 2 . This CSinduced potentiation decreased with continued pairing of the CS and the startle stimulus, being less pronounced on Training Day 3 than on Training Day 1. An ANOVA of this pattern of results for the training sessions yielded a significant difference between groups, $F(1,22)=26.42, p<.001$, a significant effect of sessions, $F(8,176)=13.91, p<.001$, and a significant Group $\times$ Sessions interaction, $F(8,176)=3.67, p<.01$.

The freezing data for the three training days and the two test days are shown in Figure 4. These data paralleled the startle response data. The paired group froze more overall during the periods sampled than did the unpaired group, and this group difference decreased over training sessions. An ANOVA of this pattern yielded a significant group effect, $F(1$, $22)=15.07, p<.01$, and sessions effect, $F(8,176)=91.18$, $p<.001$, and a significant Group $\times$ Sessions interaction, $F(8$, $176)=4.53, p<.001$. The development of the discrimination between CS and non-CS periods began to appear on Session 3 of Training Day 1. The paired group froze more during the CS than during non-CS periods, whereas the unpaired group showed the opposite pattern. The discrimination disappeared 
Startle Response

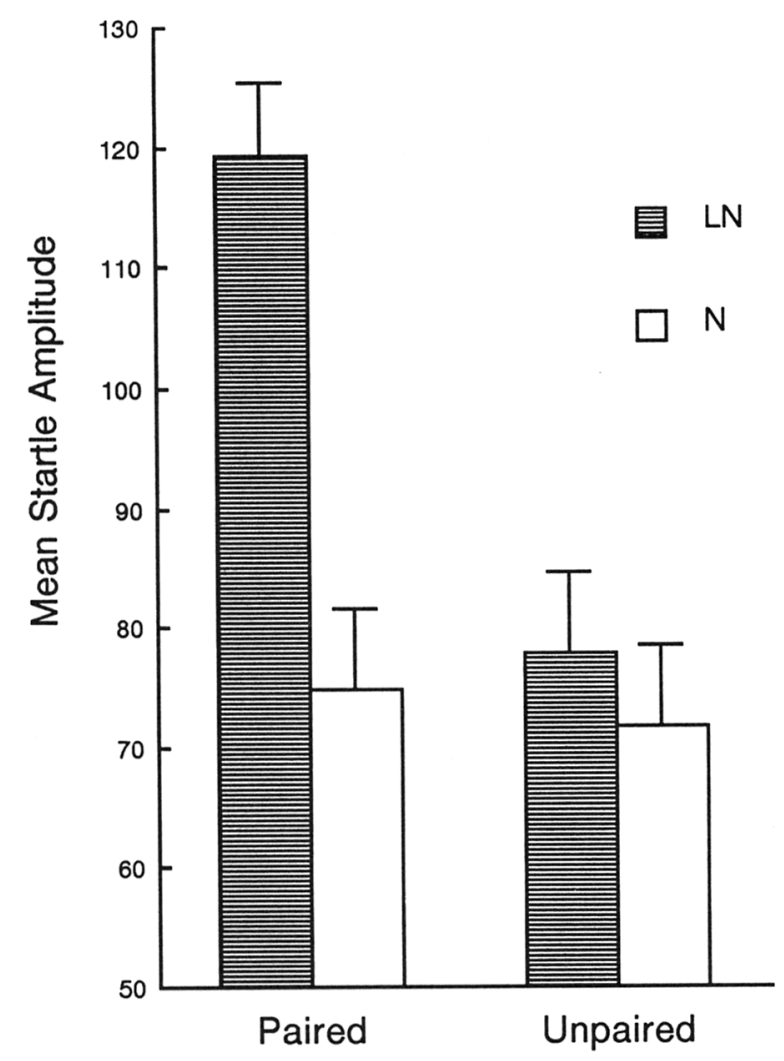

Freezing

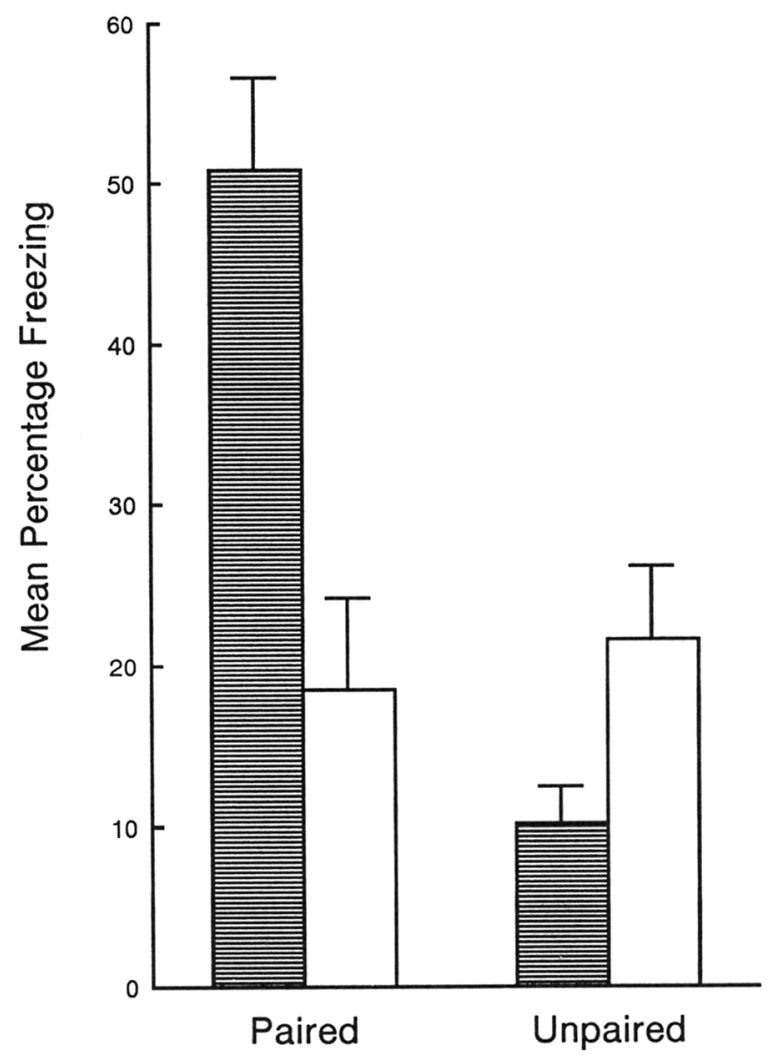

Figure 2. Mean startle amplitudes on light-noise trials $(\mathrm{LN})$ and noise-alone trials $(\mathrm{N})$ and mean percentage freezing during the light on LN trials and for the $20 \mathrm{~s}$ before the white noise startle stimulus on $\mathrm{N}$ trials for the paired and unpaired groups for Test Day 1 in Experiment 2. (Note that the ordinates for the two measures are scaled differently and have different starting points. Vertical lines indicate standard errors.)

along with the freezing response. An analysis of this pattern of results for the training sessions yielded a significant CS effect, $F(1,22)=67.26, p<.001$, and significant interactions of CS $\times$ Group, $F(1,22)=84.85, p<.001, \mathrm{CS} \times$ Sessions, $F(8,176)=5.16, p<.001$, and CS $\times$ Group $\times$ Sessions, $F(8$, 176) $=9.42, p<.001$.

As is shown in the last panel of Figures 3 and 4, the group and CS differences found on Test Day 1 had largely disappeared by Test Day 2. An ANOVA of the startle response data on Test Day 2 found no significant group or trial-type differences or interactions (all $F \mathrm{~S}<1$ ). Although very little freezing behavior remained by Test Day 2, when it did occur, it was during the CS period for the paired group. For the three sessions, this group showed $2.9 \%$ freezing on $\mathrm{LN}$ trials and $0.1 \%$ on $\mathrm{N}$ trials. The unpaired group showed $0.3 \%$ freezing on both $\mathrm{LN}$ and $\mathrm{N}$ trials. An ANOVA of these freezing differences yielded a significant group difference, $F(1,22)=$ $11.52, p<.01$, trial-type difference, $F(1,22)=12.24, p<$ .01 , and Group $\times$ Trial Type interaction, $F(1,22)=12.39, p$ $<.01$.

The session means displayed in Figures 3 and 4 provide a convenient and accurate summary of the full course of train- ing and testing, but they do not reveal the trial-by-trial development of the group and CS differences. The group differences in startle and freezing developed rapidly within Session 1 of Training Day 1, leading to the differences shown by the session means. The discrimination between the CS and nonCS periods on the freezing measure began to develop during Session 1 of Training Day 1 but only became clearly apparent during Session 3, as the session means in Figure 4 reveal. It is important to note that the groups did not differ in either startle or freezing on Trial 1, Session 1. The mean startle amplitudes on this trial were $83.8 \pm 18.6$ and $75.6 \pm 14.2$ for the paired and unpaired groups, respectively, $t<1$ ). No animal was rated as freezing before Trial 1 , Session 1 , Test Day 1. The differences on both measures developed as the animals experienced the CS-startle stimulus contingencies.

\section{Discussion}

The results from Test Day 1 basically replicated the results from Experiment 1 in showing that a CS previously paired with a startle stimulus could serve to potentiate the response 
Train 1

Test 1

Train 2

Train 3

Test 2
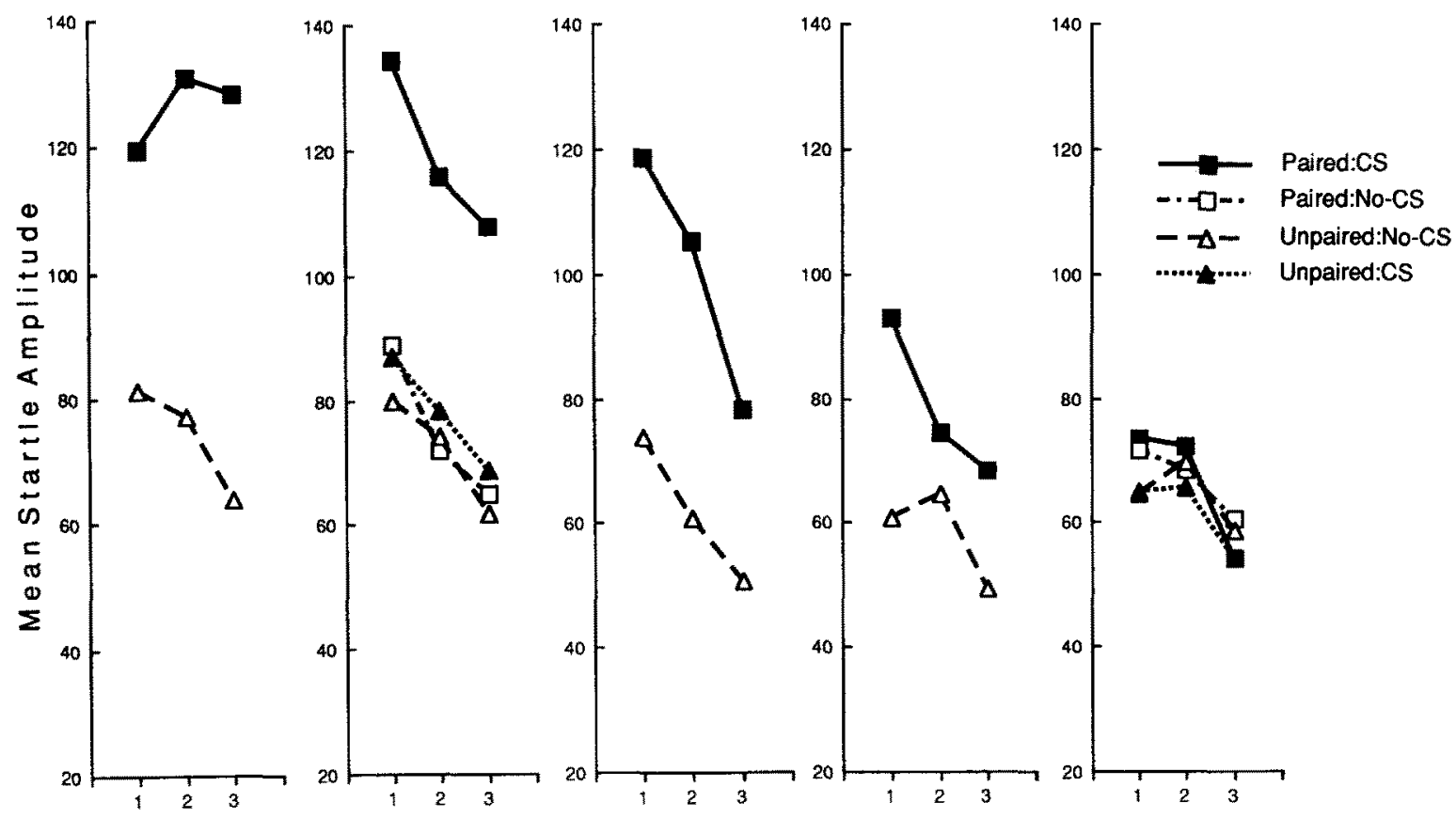

Sessions

Figure 3. Mean startle amplitudes for each session across all training and test days for the paired and unpaired groups for stimuli either preceded by the light CS or presented alone (No-CS). (On training days, all stimuli were preceded by the CS for the paired group and were presented alone for the unpaired group.)

to a startle stimulus presented in its presence. These results provide the logical extension to Experiment 1 by showing that the response to the same startle stimulus used as the US in training to establish the potentiating CS is itself potentiated in the presence of the CS. As in Experiment 1, animals in the paired group froze more during the CS than during the nonCS periods. The CS inhibited freezing in the unpaired group because this group froze less during CS periods than during non-CS periods. This inhibitory pattern was suggested but did not reach significance in Experiment 1. In neither experiment was there a significant difference between startle response amplitudes on CS and non-CS trials for the unpaired group. This suggests that the startle response may be a somewhat less sensitive index of the contingencies than the freezing measure. By Test Day 2, the CS had lost its power to potentiate startle and retained only the slightest ability to induce freezing. The 60 pairings of the $C S$ and the startle stimulus that intervened between Test Day 1 and Test Day 2 eliminated the effectiveness of the startle stimulus as a US.

During training, pairing the startle stimulus with the CS potentiated responding and retarded the course of response decrements in the paired group. It was the light as a CS for the startle stimulus, and not the light alone, that elevated startle amplitudes. The two groups showed similar startle amplitudes on Trial 1, Session 1, Training Day 1. On this trial, before any CS-startle stimulus pairings, the light had no significant effect on the startle amplitude of the paired group. Similarly, the light had no potentiating effect on the unpaired group on Test Day 1, and when the light was removed from the paired group on $\mathrm{N}$ trials on Test Day 1, that group's response level fell to the level of the unpaired group. The simple manipulation of providing a stimulus to predict the onset of the startle stimulus potentiated startle amplitudes and retarded the course of between-sessions habituation.

\section{General Discussion}

The data from these two experiments support in detail the hypothesis outlined in the introduction. A startle stimulus in a standard habituation paradigm can serve as a US for fear conditioning, and the fear CS serves in turn to potentiate the response to the startle stimulus. With repeated presentations, the startle stimulus loses its fear-provoking qualities. When a CS consistently predicts the startle stimulus throughout training, responses to that stimulus are elevated, and any response decrements are retarded.

Borszcz, Cranney, and Leaton (1989) hypothesized that the standard startle habituation paradigm contains the elements of Pavlovian fear conditioning. In that experiment, the contextual cues of the startle chamber served as the CS, and the 


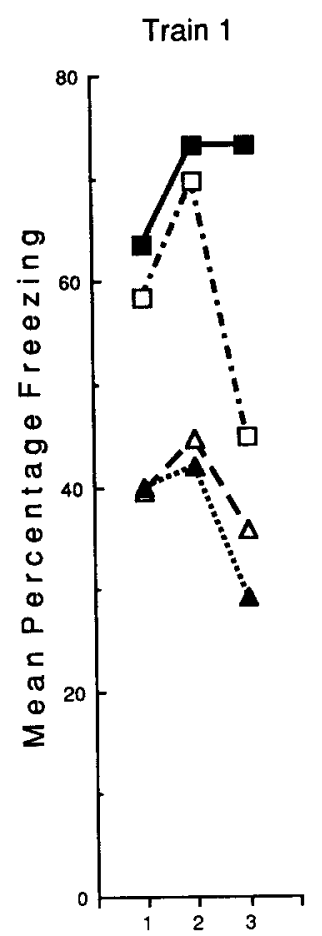

Test 1

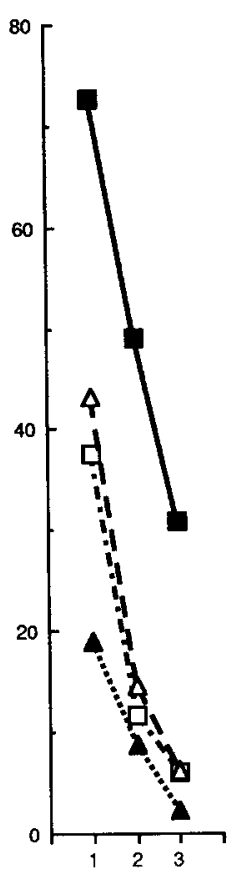

Train 2

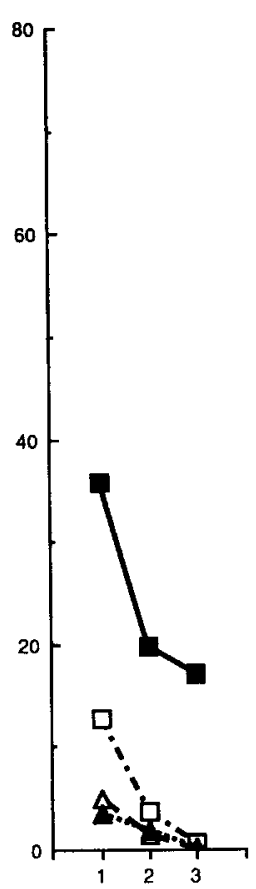

Sessions
Train 3

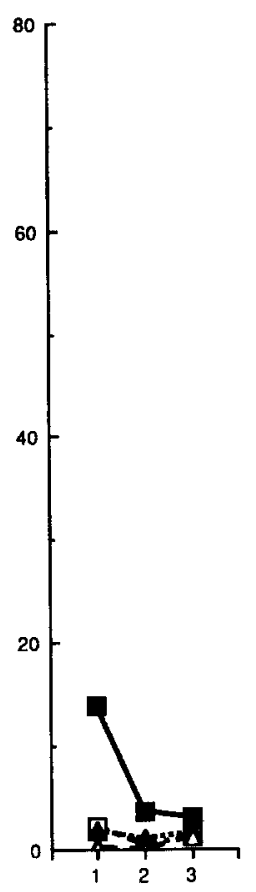

Test 2

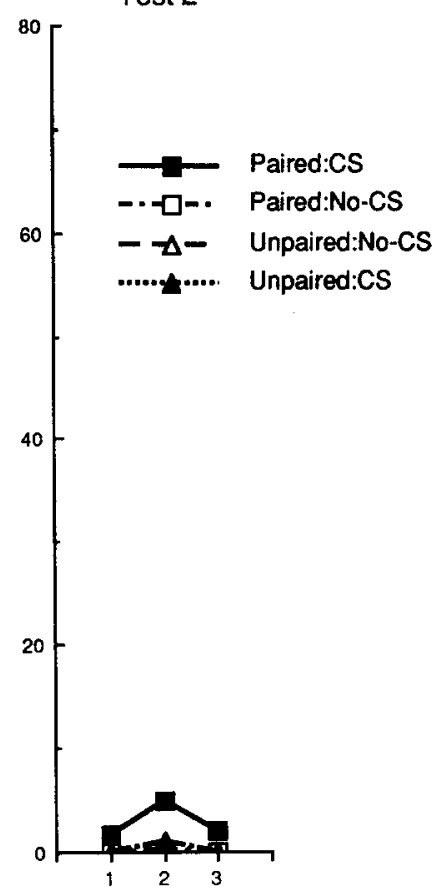

Figure 4. Mean percentage freezing for each session across all training and test days for the paired and unpaired groups during the CS or during equivalent non-CS periods (No-CS).

startle stimulus served as the US. Fear conditioning was indexed by the development of freezing to the context. According to this hypothesis, fear conditioning elevates startle amplitudes through the response-energizing effects that accompany the central fear state. In the present experiments, a discrete CS, rather than the context, was associated with the startle stimulus, and this CS served to elevate startle amplitudes. Fear conditioning was indexed by differential freezing to this discrete CS. In the Borszcz et al, experiment, preexposure to the context served as a latent inhibition manipulation that retarded the development of freezing and minimized the fear-induced elevations of startle amplitudes. Preexposure in the present experiments likewise should have retarded acquisition of fear to the context, but it should have facilitated acquisition of fear to the discrete CS.

Borszcz, Cranney, and Leaton (1989) also found that the freezing behavior that developed early in habituation training extinguished to pretraining levels despite continued pairing of contextual cues with the startle stimulus. The nonmonotonic nature of the freezing function was explained by assuming that with extended presentations, the startle stimulus, like a weak shock (Annau \& Kamin, 1961), loses its ability to serve as an aversive US. Once the startle stimulus loses its properties as a fear-invoking stimulus, additional trials become equivalent to extinction trials for conditioned fear. In the present experiment, the $60 \mathrm{CS}$-startle stimulus pairings that intervened between Test 1 and Test 2 in Experiment 2 reduced the fear-invoking properties of the CS to near zero.
We previously discussed (Borszcz et al., 1989) the basic similarities of this model of startle response habituation with the dual-process theory of habituation (Groves \& Thompson, 1970). Both models maintain that repeated elicitation of a reflex invokes two independent and opposing processes that interact to determine response amplitudes. The habituation process is proposed to underlie response decrements, whereas the second process, sensitization, serves to enhance response amplitudes. As habituation procedes, the sensitization process itself habituates, and the habituation process is progressively unopposed by the response enhancing effects of sensitization. The conditioned fear that we find associated with startle response habituation parallels the form of the sensitization function described by dual-process theory. Our model differs from dual-process theory because we emphasize long-term processes of both habituation and sensitization. We assume, in agreement with dual-process theory, that habituation is a nonassociative process. However, we do assume that response amplitude in some habituation paradigms is influenced by an associative process that takes the form of fear conditioning, long-term sensitization.

The influence of associative variables on long-term response decrements has been described by Wagner's (1976, 1979) influential theory of habituation. He proposed that long-term habituation involves the retrieval of a memorial representation of the response-eliciting stimulus from long-term to shortterm memory. In the typical startle response paradigm, this "retrieval-generated priming" is purportedly the consequence 
of exposure to contextual cues (CS) that become associated with the eliciting stimulus (US) during habituation training. Priming renders the eliciting stimulus less "surprising" and results in a decrement in the amplitude or probability of the response. Within the framework of Wagner's theory, priming the startle stimulus with a discrete CS should make the stimulus less surprising and thus enhance response decrements. In direct contrast to this expectation, it was the primed stimulus in the present experiment that provoked the larger response. When a CS invariably predicted the occurrence of the startle stimulus, the response to that stimulus was potentiated, and response decrements were retarded. Associative processes in habituation have been consistently difficult to demonstrate (Borszcz et al., 1989; Leaton, 1976; Marlin \& Miller, 1981). However, the fear/sensitization effects described in the present experiments are associative and do serve to alter response levels. These factors provide an associative dimension to responsiveness in a startle habituation paradigm even though the habituation process itself may be nonassociative.

Our data would appear to be in conflict with data showing that an unconditioned response (UR) is often, although not invariably (e.g., Donegan, 1981), reduced in amplitude when the US is preceded by a CS, a phenomenon called conditioned diminution of the UR (Kimmel, 1966). Wagner has pointed to this phenomenon as supportive of his associative theory of habituation (Wagner, 1976, 1979; Whitlow \& Wagner, 1984). This phenomenon also provides part of the empirical support for conditioning theories (e.g., Wagner, 1981) that assume that the CR is sometimes opposite in form, and therefore antagonistic, to the UR. This assumption is central to conditioning theories of drug tolerance (Siegel, 1975). The present experiments should have been procedurally adequate to demonstrate the phenomenon. However, a CS enhanced rather than diminished the startle response as UR. We believe that the apparent conflict lies in the fact that a given US, like the auditory startle stimulus, provokes many independent responses that can be considered URs. In the present situation, we assumed that the startle stimulus provoked a painlike UR, which underlay the conditioned fear we indexed with the freezing response. This fear $\mathrm{CR}$ would be expected to diminish the pain UR just as shock-induced conditioned fear (Fanselow, 1984) and startle stimuli (Cranney, 1988) produce hypoalgesic effects. Some URs, probably those that are homeostatically relevant, initiate compensatory processes in the organism that can be brought under associative control. Other URs, even to the same US, do not initiate such processes and therefore are not directly influenced by associative variables. Obviously, we believe that the startle response represents this latter type of UR.

\section{References}

Albert, D. J., \& Walsh, M. L. (1984). Neural systems and the inhibitory modulation of agonistic behavior: A comparison of mammalian species. Neuroscience and Biobehavioral Reviews, 8 , 5-24.

Annau, Z., \& Kamin, L. J. (1961). The conditioned emotional response as a function of intensity of the US. Journal of Comparative and Physiological Psychology, 54, 428-432.

Bakal, C. W., Johnson, R. D., \& Rescorla, R. A. (1974). The effect of change in US quality on the blocking effect. Pavlovian Journal of Biological Science, 9, 97-104.

Blanchard, R. J., \& Blanchard, D. C. (1969). Crouching as an index of fear. Journal of Comparative and Physiological Psychology, 67, 370-375.

Blanchard, R. J., \& Blanchard, D. C. (1972). Innate and conditioned reactions to threat in rats with amygdaloid lesions. Journal of Comparative and Physiological Psychology, 81, 281-290.

Borszcz, G. S., Cranney, J., \& Leaton, R. N. (1989). Influence of longterm sensitization on long-term habituation of the acoustic startle response in rats: Central gray lesions, preexposure, and extinction. Journal of Experimental Psychology: Animal Behavior Processes. $15,54-64$.

Brown, J. S., Kalish, H. I., \& Farber, I. E. (1951). Conditioned fear as revealed by magnitude of startle response to an auditory stimulus. Journal of Experimental Psychology, 41, 317-328.

Cranney, J. (1987). Startle responding and context conditioning: Naloxone pretreatment and stimulus intensity. Pavlovian Journal of Biological Science, 22, 47-51.

Cranney, J. (1988). Analgesia following startle-eliciting stimuli. Psychobiology, 16, 67-69.

Davis, M., \& Astrachan, D. L. (1978) Conditioned fear and startle magnitude: Effects of different footshock and backshock intensities used in training. Journal of Experimental Psychology: Animal Behavior Processes, 4, 95-103.

Donegan, N. H. (1981). Priming-produced facilitation or diminution of responding to a Pavlovian unconditioned stimulus. Journal of Experimental Psychology: Animal Behavior Processes, 7, 295-312.

Fanselow, M. S. (1980). Conditional and unconditional components of post-shock freezing. Pavlovian Journal of Biological Sciences, 15, 177-182.

Fanselow, M. S. (1984). Shock-induced analgesia on the formalin test: Effects of shock severity, naloxone, hypophysectomy, and associative variables. Behavioral Neuroscience, 98, 79-95.

Groves, P. M., \& Thompson, R. F. (1970). Habituation: A dualprocess theory. Psychological Review, 77, 419-450.

Hitchcock, J., \& Davis, M. (1986). Lesions of the amygdala, but not of the cerebellum or red nucleus, block conditioned fear as measured with the potentiated startle paradigm. Behavioral Neuroscience, 100, 11-22.

Kimmel, H. D. (1966). Inhibition of the unconditioned response in classical conditioning. Psychological Review, 73, 232-240.

Leaton, R. N. (1976). Long-term retention of the habituation of lick suppression and startle response produced by a single auditory stimulus. Journal of Experimental Psychology: Animal Behavior Processes, 2, 248-259.

Leaton, R. N., \& Borszcz, G. S. (1985). Potentiated startle: Its relation to freezing and shock intensity in rats. Journal of Experimental Psychology: Animal Behavior Processes, 11, 421-428.

Leaton, R. N., \& Supple, W. F., Jr. (1987). The amygdala, long-term habituation of the acoustic startle response, and freezing in rats. Society of Neuroscience Abstracts, 13, 644.

Leitner, D. S., \& Rosenberger, M. C. (1983). A simple and inexpensive startle transducer with high output. Behaviour Research Methods and Instrumentation, 15, 508-510.

LoLordo, V. M. (1967). Similarity of conditioned fear responses based upon different aversive events. Journal of Comparative and Physiological Psychology, 64, 154-158.

Lyon, M. (1964). The role of central midbrain structures in conditioned responding to aversive noise in the rat. Journal of Comparative Neurology, 122, 407-429. 
Marlin, N. A., \& Miller, R. R. (1981). Associations to contextual stimuli as a determinant of long-term habituation. Journal of Experimental Psychology: Animal Behavior Processes, 7, 313-333.

Siegel, S. (1975). Evidence from rats that morphine tolerance is a learned response. Journal of Comparative and Physiological Psychology, 89, 498-506.

Wagner, A. R. (1976). Priming in STM: An information-processing mechanism for self-generated or retrieval-generated depression in performance. In T. J. Tighe \& R. N. Leaton (Eds.), Habituation: Perspectives from child development, animal behavior, and neurophysiology (pp. 95-128). Hillsdale, NJ: Erlbaum.

Wagner, A. R. (1979). Habituation and memory. In A. Dickinson \& R. A. Boakes (Eds.), Mechanisms of learning and motivation (pp.
53-82). Hillsdale, NJ: Erlbaum.

Wagner, A. R. (1981). SOP: A model of automatic memory processing in animal behavior. In N. E. Spear \& R. R. Miller (Eds.), Information processing in animals: Memory mechanisms (pp. 5-47). Hillsdale, NJ: Erlbaum.

Whitlow, J. W., Jr., \& Wagner, A. R. (1984). Memory and habituation. In H. V. S. Peeke \& L. Petrinovich (Eds.), Habituation, sensitization, and behavior (pp. 103-153). Orlando, FL: Academic Press.

Received July 21, 1989

Revision received November 17, 1989 Accepted December 4, 1989

\section{Low Publication Prices for APA Members and Affiliates}

Keeping You Up-to-Date: All APA members (Fellows; Members; and Associates, and Student Affiliates) receive--as part of their annual dues--subscriptions to the American Psychologist and the APA Monitor.

High School Teacher and Foreign Affiliates receive subscriptions to the APA Monitor and they can subscribe to the American Psychologist at a significantly reduced rate.

In addition, all members and affiliates are eligible for savings of up to 50\% on other APA journals, as well as significant discounts on subscriptions from cooperating societies and publishers (e.g., the British Psychological Society, the American Sociological Association, and Human Sciences Press).

Eseential Recources: APA members and affiliates receive special rates for purchases of APA books, including the Publication Manual of the APA, the Master Lectures, and APA's Guide to Research Support.

Other Benefits of Membership: Membership in APA also provides eligibility for low-cost insurance plans covering life; medical and income protection; hospital indemnity; accident and travel; Keogh retirement; office overhead; and student/school, professional, and liability.

For more information, write to American Paychological Association, Membership Services, 1200 Seventeenth Street NW, Washington, DC 20036, USA. 